\title{
Operative versus Non-Operative Management of Traumatic Thoracolumbar Injuries according to the AO Spine Thoracolumbar Spine Injury Classification System
}

\section{Tratamento cirúrgico versus conservador das lesões traumáticas toracolombares segundo o Sistema de Classificação AOSpine das Lesões Toracolombares}

\begin{abstract}
Andrei F. Joaquim ${ }^{1}$ (D)
${ }^{1}$ Department of Neurology, Universidade Estadual de Campinas
(UNICAMP), Campinas, SP, Brazil
\end{abstract}

Arq Bras Neurocir 2020;39(3):181-188.

\author{
Address for correspondence Andrei F. Joaquim, MD, PhD, \\ Departamento de Neurologia, Disciplina de Neurocirurgia, \\ Universidade Estadual de Campinas (UNICAMP), Cidade Universitária \\ Zeferino Vaz, Campinas, SP, 13083-970, Brazil \\ (e-mail: andjoaquim@yahoo.com).
}

Introduction The AOSpine Thoracolumbar Spine Injury Classification (AOSTSIC) system has been proposed to better characterize injury morphologies and improve the classification of thoracolumbar (TL) spine trauma. However, the indications for surgical treatment according to the AOSTSIC system are still debated. Additionally, the proposed Thoracolumbar AOSpine Injury Score (AOSIS) is quite complex, which may preclude its use in daily practice. The objective of this review is to discuss the AOSTSIC system and its indications for initial nonoperative versus surgical management of acute TL spine trauma.

Methods We analyzed the literature for each injury type (and subtype, when pertinent) according to the AOSTSIC system as well as their potential treatment options.

Results Patients with AOSTSIC subtypes A0, A1, and A2 are neurologically intact in the vast majority of the cases and initially managed nonoperatively. The treatment of A3- and A4-subtype injuries (burst fractures) in neurologically-intact patients is still debated with great controversy, with initially nonoperative management being considered an option in select patients. Surgery is recommended when there are neurological deficits or failure of nonoperative management, with the role of magnetic resonance findings in the Posterior Ligamentous Complex (PLC) evaluation still being considered controversial. Injuries classified as type B1 in neurologically-intact patients may be treated, initially, with nonoperative management, provided that there are no ligamentous injury and non-displacing fragments. Due to severe ligamentous injury, type-B and type- $C$ injuries should be considered as unstable injuries that must be surgically treated, regardless of the neurological status of the patient.

Conclusions Until further evidence, we provided an easy algorithm-based guide on the spinal trauma literature to help surgeons in the decision-making process for the treatment of TL spine injuries classified according to the new AOSTSIC system. received

August 4, 2019

accepted after revision

August 21, 2019
DOI https://doi.org/

10.1055/s-0039-1700578. ISSN 0103-5355.
Copyright ( $\odot 2020$ by Thieme Revinter

Publicações Ltda, Rio de Janeiro, Brazil
License terms

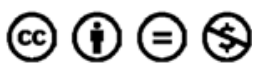




\section{Introduction}

In 2013, the AOSpine Trauma Knowledge Forum published the AOSpine Thoracolumbar Spine Injury Classification (AOSTSIC) system (-Annex 1 - Available online). ${ }^{1}$ This new classification of Thoracolumbar spine traumatic injuries was made by an international group of academic spine surgeons in an attempt to improve the previous Thoracolumbar Injury Classification System (TLICS) and to incorporate morphological characteristics of the Magerl classification, such as grading injuries severity in a crescent manner. ${ }^{2,3}$

A systematic review by Abedi et al on the reliability and validity of the AOSTSIC system was recently published. ${ }^{4}$ The authors reported that there is moderate evidence for good intraobserver reliability among injury types and moderate evidence of poor interobserver reliability when all subtypes were included. For injuries modifiers, such as indeterminate injury to the tension band based on magnetic resonance imaging (MRI) findings and patients' comorbidities, the reliability is unknown. Based on this review, we can conclude that grouping injuries according to type may improve reliability, facilitate communication among health care providers and allow for comparison of surgical results in different spinal centers with better validity than assessment of injury subtypes.

In 2016, Kepler et al reported the results of a spine survey to develop the AOSTSIC system. ${ }^{5}$ They proposed that injuries should receive 1 point for $A 1,2$ points for $A 2$, and 3 points for A3 subtypes. For A4 and B1 subtypes, the injury should receive 5 points. For B2 subtype, 6 points, 7 for B3 subtype, and 8 for $C$ subtype. Regarding the neurological status, no points for intact (N0), 1 for transient neurological status (N1), 2 for radicular symptoms (N2), and 4 points for incomplete (N3) or complete (N4) neurological deficits. For patients with an indeterminate posterolateral ligamentous complex injury (M1), 1 additional point was counted. According to the authors, the score was not a proposal of a treatment guideline. Although very interesting, we personally believe that such a complex way to score injuries may result in low clinical application. Differently from the TLICS, which is much simpler, this new score system would require a deep knowledge of the $\mathrm{AO}$ system and a lot of time to be applied in daily practice.

Considering that, the AOSTSIC is the most recent and widespread classification for traumatic thoracolumbar (TL) injuries, and, due to the lack of studies proposing treatment guidelines according to injury types, we performed this review in an attempt to offer the best management for acute TL spine trauma considering injury type and the neurological status of the patient.

\section{Methods}

A narrative review of the spine trauma literature using manual searches in the Medline database (National Library of Medicine) was performed to subsidize the specific treatment of each injury described in the AOSTSIC. We searched specifically for articles related to cases series reporting the treatment for each injury type (and subtype, when pertinent) proposed by the AOSTSIC system. The reason for including only case series in our search was that, with exception of burst fractures without neurological deficits, comparative studies on the outcomes of different traumatic injuries are missing in the spine literature. Articles related to the manuscript that discussed the AOTSIC system were also included, according to the purpose of our review.

\section{Results}

Independently of their neurological status, patients with AOSTSIC subtypes A0 to A2 (compression injuries) are initially managed nonoperatively, except if they have some soft tissue compressing the neural tissue that can lead to neurological deficits, such as a traumatic disc herniation, which requires further radiological investigation. ${ }^{6-9}$ Using the TLICS score, these injuries were given zero, 1, or 2 points, receiving conservative treatment in cases series previously published with reasonable outcomes. ${ }^{6-8}$

\section{Type A - Subtypes A0-1-2}

\section{Neurologically Intact (N0 and N1)}

Minor compression injuries are mechanically stable, and many clinical series reported successful treatment with nonoperative management. ${ }^{6-9}$ However, some patients may still have chronic pain after the treatment of these fractures, despite being mechanically stable. ${ }^{10}$

\section{Neurological Deficits (Radicular - N2, Incomplete - N3 and Complete - N4)}

It is quite unusual for types $\mathrm{A} 0, \mathrm{~A} 1$, and $\mathrm{A} 2$ (minor bone fractures, compression fractures and split fractures) to have neurological deficits, even in large case series. ${ }^{7}$ In this setting, further MRI investigation may be necessary as well as dynamic radiological exams to detect soft tissue compression (such as a disc herniation leading to radicular symptoms) or occult ligamentous injury and inadequate injury classification. ${ }^{9,11}$

-Fig. 1 illustrates the decision-making process of type A (subtypes A0, A1, and A2 injuries) according to the neurological status of the patient.

\section{Types A3-A4 (Incomplete and Complete Burst Fractures)}

\section{Neurologically Intact (N0 and N1)}

Burst fractures without neurological deficits are the most controversial issue in the management of acute thoracolumbar spine fractures. Some authors propose surgical treatment when there are burst fractures with segmental kyphosis (greater than $20^{\circ}$ ), when there is loss of more than $50 \%$ of vertebral body height, or when at least $50 \%$ of the canal is compromised by posterior wall fragments. ${ }^{12-15}$ Although this criteria for surgery may be adopted in many centers around the world, with regional variations, the lack of solid evidence about specific radiological parameters to guide treatment still persists. Unstable burst fractures, with posterior ligament rupture characterized by dislocation of the facet joints, diastasis of the spinous process, and subluxations, should be considered as B2 


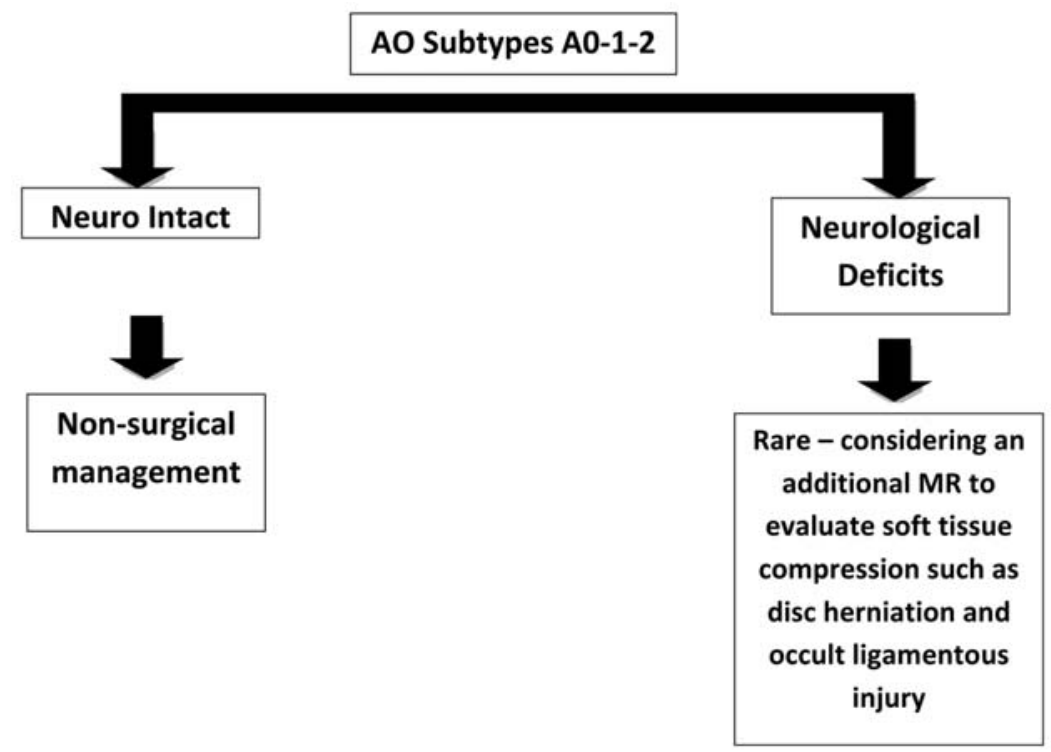

Fig. 1 Management of $\mathrm{AO}$ subtypes $\mathrm{A} 0, \mathrm{~A} 1$, and $\mathrm{A} 2$ according to the neurological status of the patient. Abbreviation: MR, magnetic resonance.

injuries (flexion-distractive mechanism) with a burst component. ${ }^{7,15-17}$ Finally, another question that needs further investigation is if there is any difference in the outcome of incomplete (A3) versus complete (A4) burst fractures, which have been evaluated together in the spinal trauma literature until the advent of the AOSTSIC. As far as we know, there is no specific radiological characteristic of a burst fracture in a neurologically intact patient that may guide operative versus nonoperative management. ${ }^{14}$

Systematic literature reviews of the conflicting results of randomized studies comparing operative versus nonoperative management of burst fractures reported that there is no evidence to support one treatment over the other, with potentially lower complication rates and less costs with conservative management. ${ }^{19-21}$ Based on this, we propose that an initial nonoperative management should be offered to these patients with very close clinical and radiological followup. ${ }^{11,19}$ In our practice, we routinely perform an MRI scan and standing plain radiographs before discharging patients to our outpatient facility with the diagnosis of an occult posterior ligamentous injury, as proposed by Mehta et al. ${ }^{22}$ Additionally, patients that are not able to ambulate with the help of pain medication may be referred for surgical treatment.

\section{Neurological Deficits (Radicular - N2, Incomplete - N3 and Complete - N4)}

Surgical treatment is well accepted for burst fractures with neurological deficits. ${ }^{2,19,23}$ Anterior, posterior, and combined approaches have been described, although posterior approaches present potentially less complications. ${ }^{2,19,23}$ We did not find any recent study proposing nonoperative management for burst fractures in neurologically-compromised patients. With few exceptions, a mild radiculopathy (N2) associated with a burst fracture may be treated nonoperatively. ${ }^{24}$

Of note, Roberts et al reported in 1970 that the nonoperative management of 7 patients with complete neurological deficits and burst fractures resulted in spinal deformity, suggesting that surgery is advisable despite a poor neurological outcome to avoid posttraumatic kyphosis. ${ }^{25}$

-Fig. 2 illustrates the decision-making process of type A3 and A4 injuries according to neurological status.

\section{Subtype B1 - “Chance” Fractures or Monosegmental Osseous Failure of the Posterior Tension Band Extending into the Vertebral Body - Pedicular Bone Fractures}

The first description of this type of fracture was in 1948 by Chance GQ, in the upper lumbar spine. ${ }^{26}$ It is usually the consequence of a flexion-distraction injury and associated with seatbelt use, the pure bony injury extending from posterior to anterior through the spinous process, pedicles, and, finally, the vertebral body, generally associated with visceral injuries, such as bowel rupture. ${ }^{26}$

\section{Neurologically Intact (N0 and N1)}

Nonoperative treatment of neurologically-intact patients with only osseous fractures is accepted in non-displaced fractures without moderate or severe kyphotic angulation. ${ }^{27-29}$ However, late neurological deterioration and kyphosis have been reported after non-operative management. ${ }^{29,30}$ In the majority of the cases series reported in the literature, operative management is preferentially offered to this group of patients, providing early stability. This is the same opinion of this author (AFJ). A posterior approach with instrumentation is sufficient to restore stability, and percutaneous fixation is an option in cases in which neural decompression is not necessary. ${ }^{28}$

Neurological Deficits (Radicular - N2, Incomplete - N3 and Complete - N4)

For patients with B1 injuries and neurological deficits, surgical treatment is well accepted in the majority of the cases to improve neurological outcome and avoid deformities. ${ }^{8,29}$

-Fig. 3 illustrates the decision-making process of subtype B1 injuries according to neurological status. In - Fig. 4, an illustrative case of a B1 fracture is presented. 
184 Surgical management according to the AO Classification Joaquim

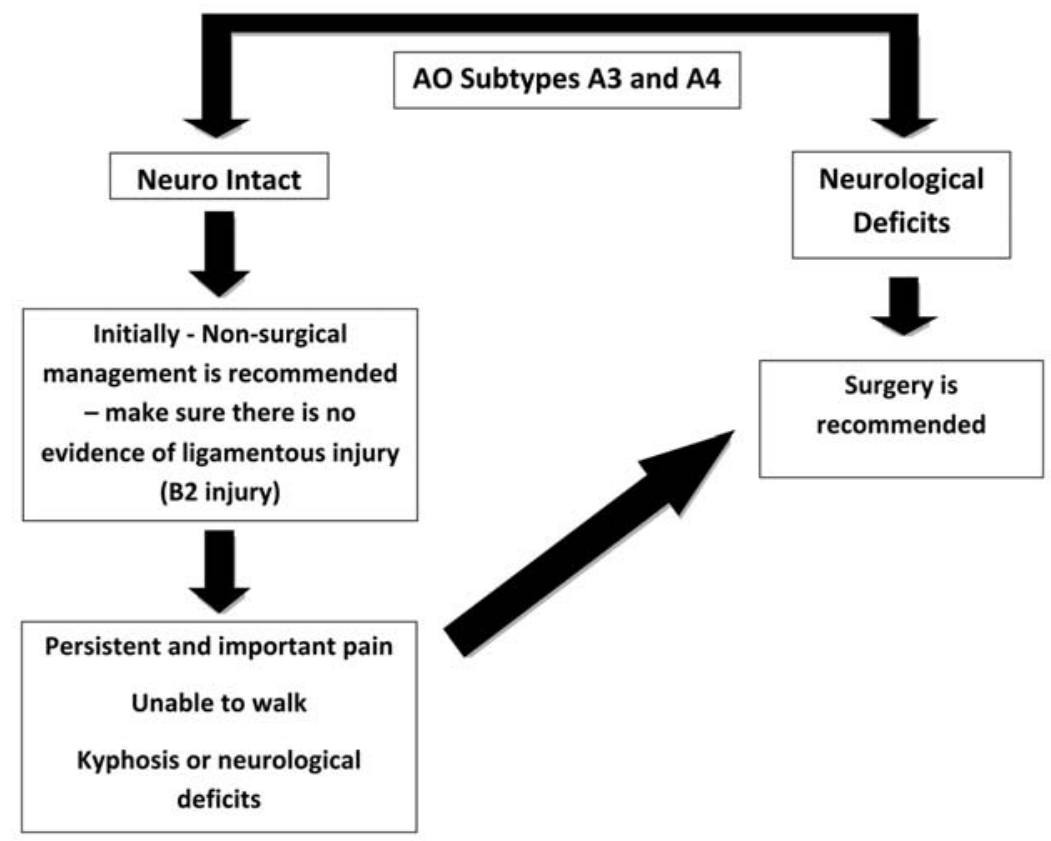

Fig. 2 Management of AO subtypes A3 and A4 (burst fractures) according to the neurological status of the patient.

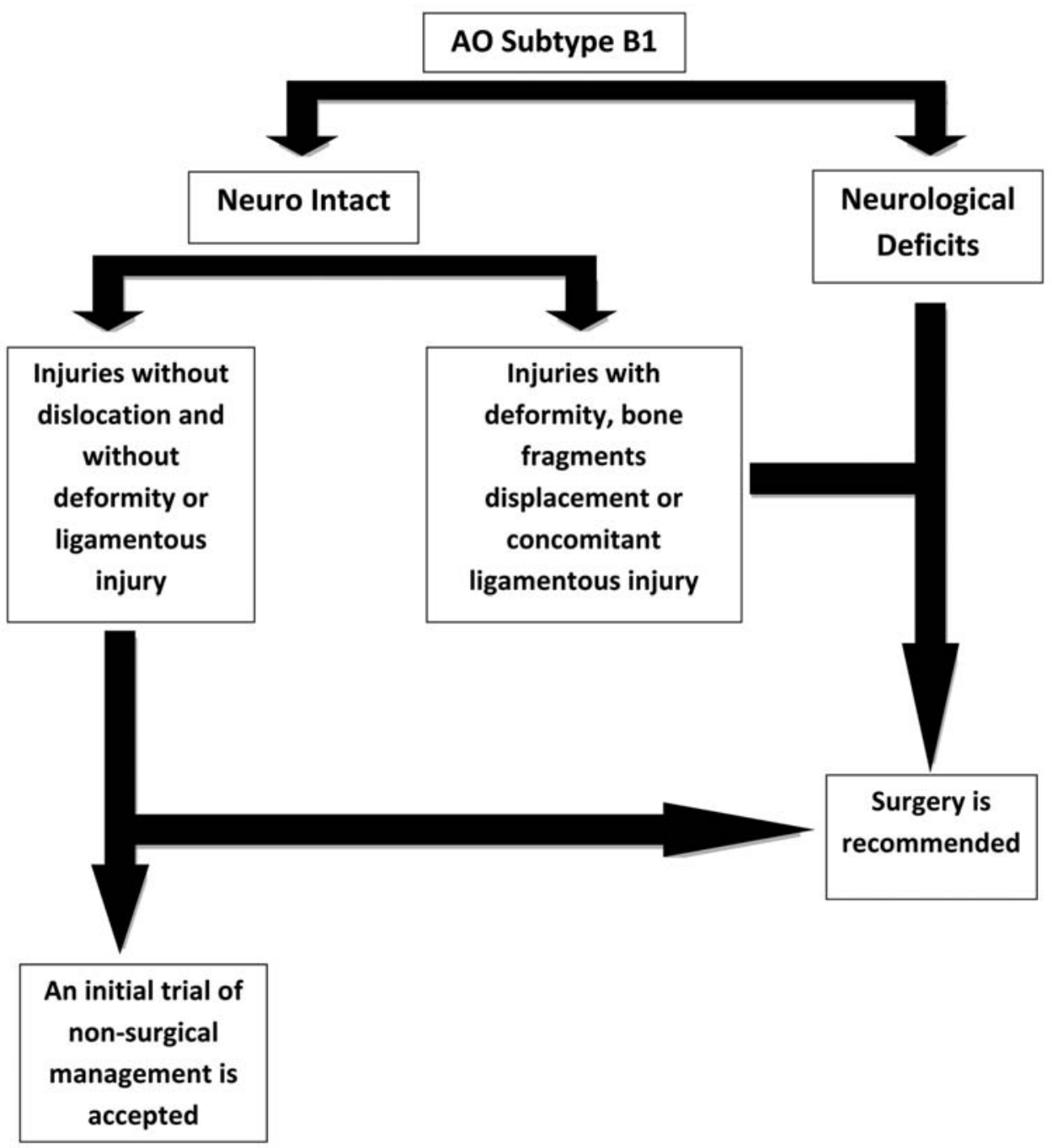

Fig. 3 Management of AO subtype B1 according to patient's neurological status. 


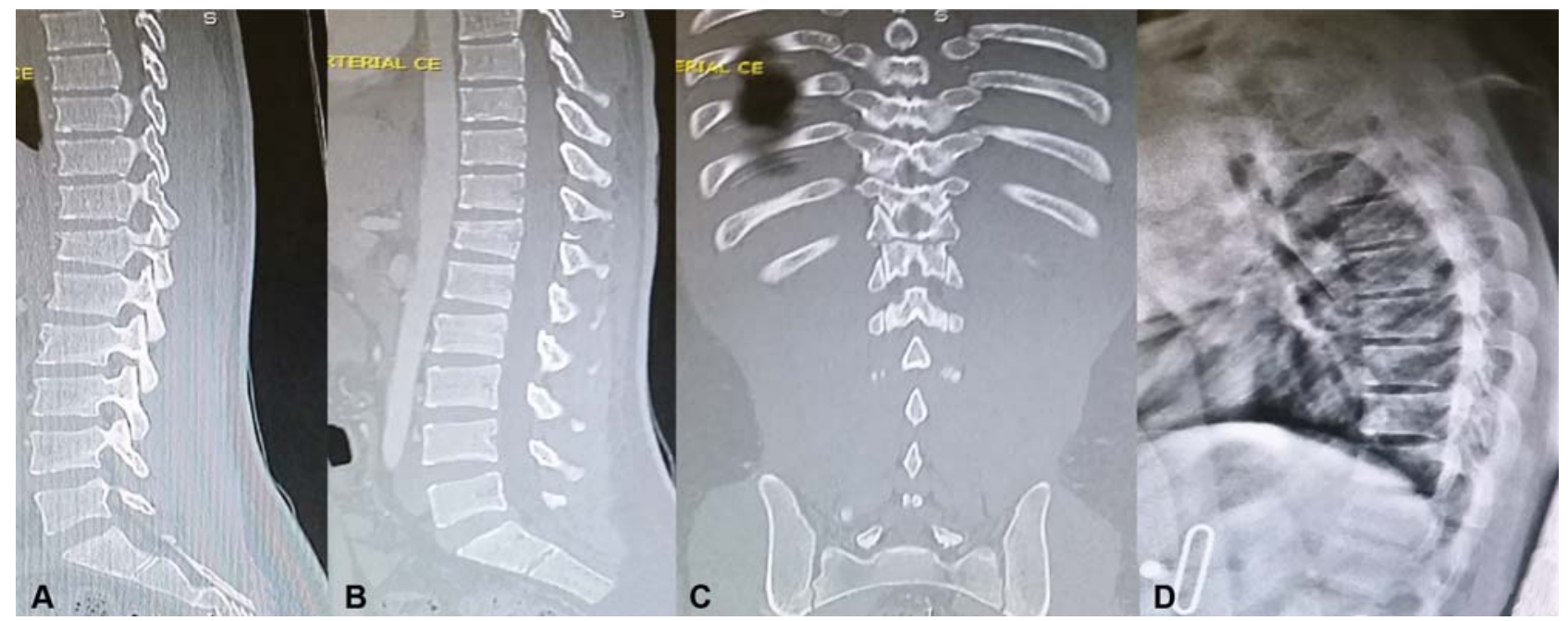

Fig. 4 Sagittal computed tomography scan of a T12 subtype B1 (Chance) fracture showing pedicle fracture (A) and some vertebral body compression (B) at T12. Coronal CT scan showing a compression fracture from pedicle to pedicle passing through the lamina of T12. The patient was walking with mild pain and no neurological deficits, asking for a trial of non-operative management. Standing lateral thoracic plain radiograph with a brace (D).

\section{Subtypes B2, B3, and Type-C Injuries}

These types of injury present severe ligamentous damage, and, thus, surgical treatment is recommended, regardless of the neurological status of the patient (N0 to N4), in order to avoid nonunion and late kyphotic deformities. ${ }^{31-33}$

For neurologically-intact patients, surgery is indicated to restore spinal stability. For patients with neurological deficits, surgery is recommended not only to restore stability but also to decompress the neural tissue and optimize the spinal cord recovery, potentially improving neurological outcomes. Nonoperative management of ligamentous injury is associated with severe pain, spinal deformity, and late neurological deterioration. ${ }^{31-33}$

-Fig. 5 illustrates the decision-making process of subtypes B2-B3 and type C. In - Fig. 6, an illustrative case of a type- $\mathrm{C}$ fracture is presented.

\section{Discussion}

In this article, we describe in a simplistic way the treatment of injuries classified according to the AOSTSIC system and neurological status. Due to the lack of prospective studies to validate our proposed management, we used the current available literature knowledge to propose the treatment of classic injury patterns that were included in the AO system. Of course, a less comprehensive evaluation may infer in treatment bias in some unusual cases, but clinical judgment is of paramount importance in spinal trauma treatment. Additionally, surgeons experience and regional characteristics should be taken into account in the decision of one treatment over the other. Finally, once the reliability of the system decreases with complexity (such as injury subtype), a more general overview is necessary instead of a detailed one,

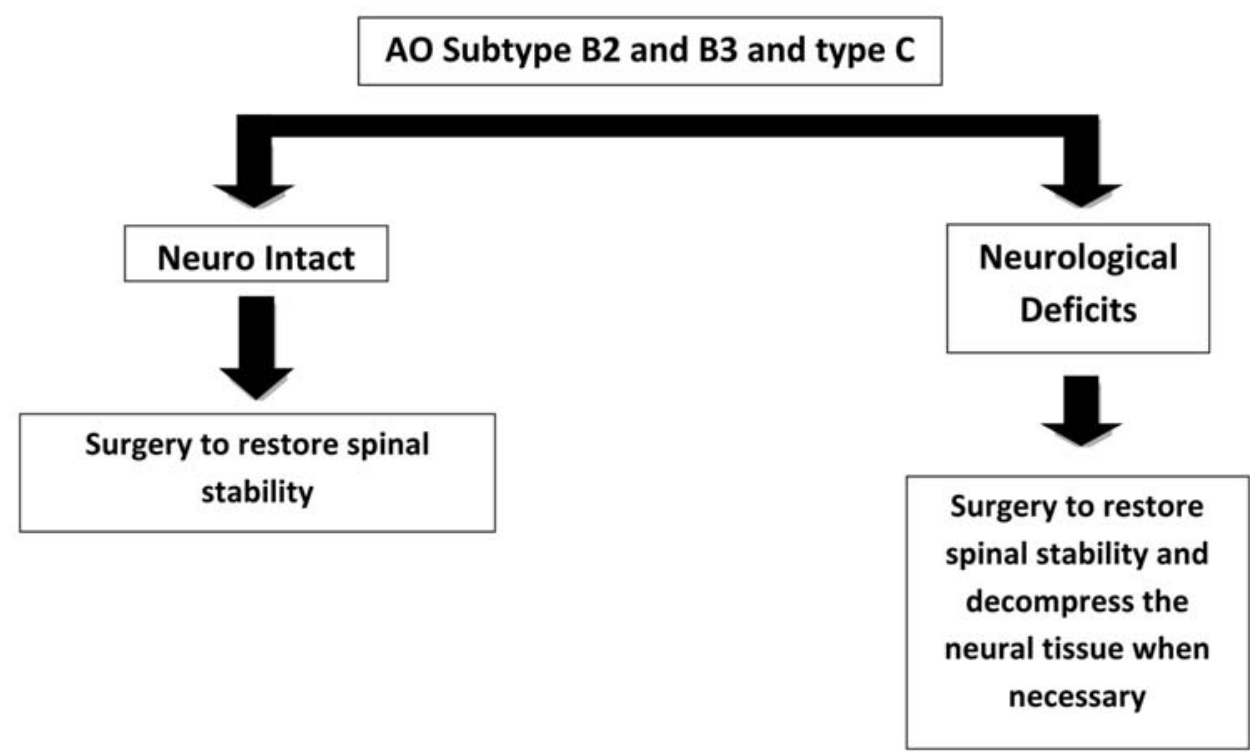

Fig. 5 Management of AO subtype B2 and B3 and type $C$ injuries according to the neurological status of the patient. 


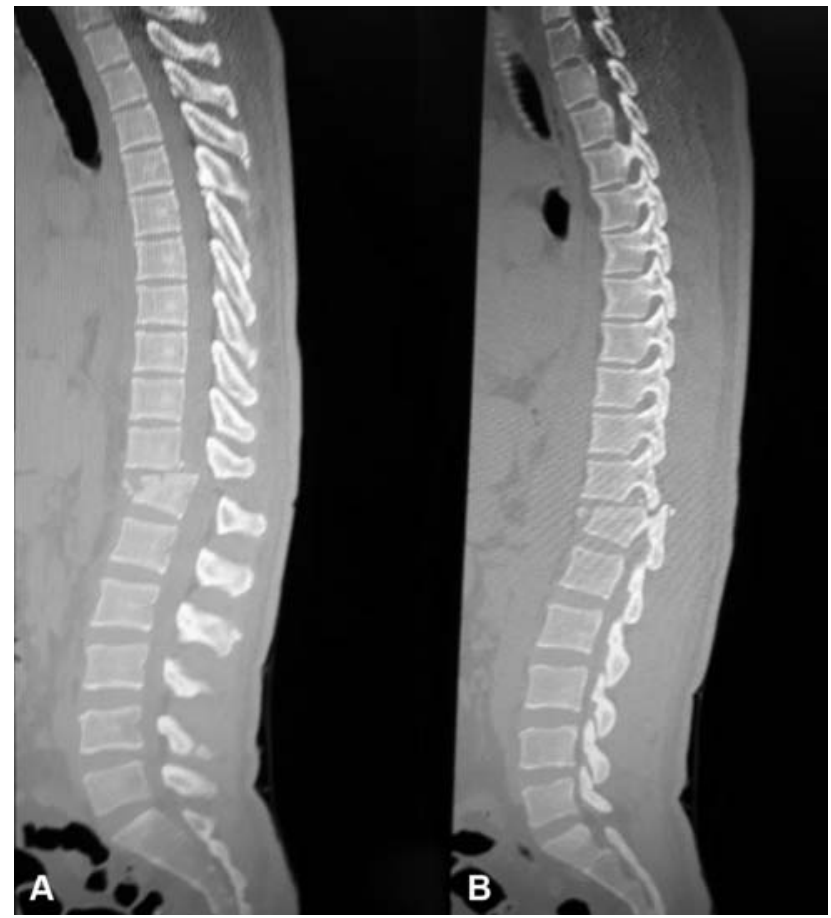

Fig. 6 Sagittal computed tomography scan of a patient with T11-12 thoracic fracture-dislocation with canal compression (A) and clear facet luxation (B). The patient had complete neurological deficit. This is a type $C$ injury requiring surgical treatment to restore spinal instability and decompress the spinal canal.

but there is no reliable classification, such as the old Magerl system.

Most of the classification systems proposed for TL spine trauma were based on expert opinion-which is characterized by a low level of evidence. ${ }^{2,3}$ Interestingly, a new classification is generally based on previous systems, in an attempt to improve previous failures or limitation of the predecessors. ${ }^{34}$ Unfortunately, the lack of comparative treatment studies for different injuries generally requires recommendations based on case series. With the exception of burst fractures without neurological deficits, which have some randomized trials with conflictive results, all the remaining injuries management were based on case series and expert opinion. ${ }^{20,21}$

Compression fractures (type A0, A1 and A2 injuries) generally heal well in patients without osteoporosis. In a retrospective study of 458 trauma patients with thoracolumbar fractures, 310 patients treated non-surgically with compression injuries were treated non-operatively, without need of late surgery. ${ }^{7}$ Pain and some degree of disability may persist in some cases. ${ }^{10}$ Comparative studies randomizing operative and nonoperative stable injuries are necessary to evaluate the benefits of pain control and the level of disability.

Probably, the most controversial problem in the management of TL fractures is the treatment of burst fractures without neurological deficits. ${ }^{35}$ Vaccaro et al reported the results of an international survey designed by the AOSpine Trauma Knowledge Forum to establish an algorithm to accompany the AOSTSIC system. They defined that injuries with less than $30 \%$ of surgeon-recommended surgical intervention should undergo a trial of initial nonoperative management, whereas injuries in which more than $70 \%$ of surgeons would recommend surgery should be operated. They reported that great controversy exists in a case, for instance, with a burst fracture (A3) with transient neurological deficits (N1) and an indeterminate PLC injury (M1)-a gray zone due to the inability of the surgeons to agree on the integrity of the PLC. The use of MRI in the evaluation of the PLC and its clinical role in the outcome should be further studied. The failure of the literature in separating A3 from A4 was an issue identified by the present study, with some surgeons from Europe, for example, having a higher tendency to recommend surgical treatment for burst fractures. Only $17.2 \%$ of the surgeons believed surgery was necessary for compression fractures (A2) without deficits, whereas for flexion distraction injuries (B2) with radicular symptoms, $81.3 \%$ of the surgeons recommended surgery. They emphasized that a potential advantage of the AOSTSIC system over the TLICS is the better characterization of type-A fractures, which may explain some geographical variability in treatment. An ongoing study sponsored by the AOSpine Trauma Knowledge forum will prospectively evaluate the outcome of A3 and A4 fractures by comparing different treatment modalities.

For more severe ligamentous injuries' patterns (all type B, with rare $\mathrm{B} 1$ exceptions, and type $\mathrm{C}$ injuries), independent of any neurological deficits, surgical treatment is recommended when there is no systemic clinical contraindication. Historical treatment of fracture-dislocation injuries with prolonged bed rest ( $\sim 10-13$ weeks on average), generally results in residual deformity and pain syndromes. ${ }^{33}$ Compared with modern case series, cases of fracture-dislocation, without neurological deficits, that are surgically treated generally have very satisfactory outcomes, most of the times with the patients returning to their normal activities. ${ }^{33}$ Additionally, for patients with neurological deficits, some neurological improvement is documented, especially in those patients with incomplete spinal cord injuries. ${ }^{8,31}$

Our review is limited, once it is based on results of case series and, thus, there is a lack of comparative treatment modalities. Additionally, pain and functional status are not commonly assessed in the spinal trauma literature. Clinical modifiers, such as patients' comorbidities, indeterminate posterior ligamentous injury, and specific osseous diseases, such as ankylosing spondylitis or diffuse idiopathic skeletal hyperostosis, were not considered, requiring a case-by-case decision. Another important factor not taken into account is spine injury location-potentially, multiple levels of fractures, injuries at the thoracic kyphosis apex, low lumbar spine, transitional TL region and middle thoracic spine may have different outcomes and biomechanical behaviors, requiring further investigation. ${ }^{36}$ However, despite all these shortcomings, our review provides useful and practical guidance for the management of TL fractures classified according to the AOSTSIC system.

\section{Conclusions}

Patients with types A0 to A2 according to the AOSTSIC system are initially managed nonoperatively. Treatment of $A 3$ and A4 fractures (incomplete and complete burst fractures) in 
neurologically-intact patients is still debated, with initial nonoperative management being considered after further radiological evaluation. Surgery is recommended in the setting of neurological deficits or failure of nonoperative management. Subtype B1 in neurologically-intact patients may be considered for nonoperative management, when there is no ligamentous injury and non-displacing injuries in selected cases. Due to severe ligamentous injury, type-B (with some rare exceptions B1) and type-C injuries should be considered unstable, independent of the neurological status of the patient, and surgically treated

\section{Conflicts of Interest}

The authors have no conflicts of interest to declare.

\section{Acknowledgments}

Acknowledgement of AOSpine and the Knowledge Forums' work. AOSpine is a clinical division of the AO Foundation-an independent medically guided nonprofit organization. The AOSpine Knowledge Forums are pathology focused working groups acting on behalf of AOSpine in their domain of scientific expertise. Each forum consists of a steering committee of up to 10 international spine experts who meet on a regular basis to discuss research, assess the best evidence for current practices, and formulate clinical trials to advance spine care worldwide. Study support is provided directly through AOSpine's Research department and AO's Clinical Investigation and Documentation unit.

\section{References}

1 Vaccaro AR, Oner C, Kepler CK, et al; AOSpine Spinal Cord Injury \& Trauma Knowledge Forum. AOSpine thoracolumbar spine injury classification system: fracture description, neurological status, and key modifiers. Spine 2013;38(23):2028-2037

2 Vaccaro AR, Lehman RA Jr, Hurlbert RJ, et al. A new classification of thoracolumbar injuries: the importance of injury morphology, the integrity of the posterior ligamentous complex, and neurologic status. Spine 2005;30(20):2325-2333

3 Magerl F, Aebi M, Gertzbein SD, Harms J, Nazarian S. A comprehensive classification of thoracic and lumbar injuries. Eur Spine J 1994;3(04):184-201

4 Abedi A, Mokkink LB, Zadegan SA, et al. Reliability and Validity of the AOSpine Thoracolumbar Injury Classification System: A Systematic Review. Global Spine J 2019;9(02):231-242

5 Kepler CK, Vaccaro AR, Koerner JD, et al. Reliability analysis of the AOSpine thoracolumbar spine injury classification system by a worldwide group of naïve spinal surgeons. Eur Spine J 2016;25 (04):1082-1086

6 Joaquim AF, Fernandes YB, Cavalcante RC, Fragoso RM, Honorato DC, Patel AP. Evaluation of the Thoracolumbar Injury Classification System in Thoracic and Lumbar Spinal Trauma. Spine (Phila Pa 1976) 2011;36(01):33-36

7 Joaquim AF, Daubs MD, Lawrence BD, et al. Retrospective evaluation of the validity of the Thoracolumbar Injury Classification System in 458 consecutively treated patients. Spine J 2013;13 (12):1760-1765

8 Joaquim AF, Ghizoni E, Tedeschi H, Batista UC, Patel AA. Clinical results of patients with thoracolumbar spine trauma treated according to the Thoracolumbar Injury Classification and Severity Score. J Neurosurg Spine 2014;20(05):562-567
9 Kumar Y, Hayashi D. Role of magnetic resonance imaging in acute spinal trauma: a pictorial review. BMC Musculoskelet Disord 2016; $17: 310$

10 Joaquim AF, Rodrigues SA, DA Silva FS, et al. Is There an Association With Spino-Pelvic Relationships and Clinical Outcome of Type A Thoracic and Lumbar Fractures Treated Non-Surgically? Int J Spine Surg 2018;12(03):371-376

11 Joaquim AF, Patel AA, Schroeder GD, Vaccaro AR. A simplified treatment algorithm for treating thoracic and lumbar spine trauma. JSpinal Cord Med 2018;7:1-11

12 Krompinger WJ, Fredrickson BE, Mino DE, Yuan HA. Conservative treatment of fractures of the thoracic and lumbar spine. Orthop Clin North Am 1986;17(01):161-170

13 Tezer M, Erturer RE, Ozturk C, Ozturk I, Kuzgun U. Conservative treatment of fractures of the thoracolumbar spine. Int Orthop 2005;29(02):78-82

14 Da Silva OT, Joaquim AF. Burst Fractures in the Thoracolumbar Junction: What Do We Know about their treatment? Arch Neurosci 2016;3(04):E39949

15 Winklhofer S, Thekkumthala-Sommer M, Schmidt D, et al. Magnetic resonance imaging frequently changes classification of acute traumatic thoracolumbar spine injuries. Skeletal Radiol 2013;42(06):779-786

16 Barcelos AC, Joaquim AF, Botelho RV. Reliability of the evaluation of posterior ligamentous complex injury in thoracolumbar spine trauma with the use of computed tomography scan. Eur Spine J 2016;25(04):1135-1143

17 Joaquim AF, Lawrence B, Daubs M, et al. Measuring the impact of the Thoracolumbar Injury Classification and Severity Score among 458 consecutively treated patients. JSpinal Cord Med 2014;37(01):101-106

18 Aleem IS, Nassr A. Cochrane in $\operatorname{CORR}(\circledR)$ : Surgical Versus Nonsurgical Treatment for Thoracolumbar Burst Fractures Without Neurological Deficit. Clin Orthop Relat Res 2016;474(03): 619-624

19 Scheer JK, Bakhsheshian J, Fakurnejad S, Oh T, Dahdaleh NS, Smith ZA. Evidence-Based Medicine of Traumatic Thoracolumbar Burst Fractures: A Systematic Review of Operative Management across 20 Years. Global Spine J 2015;5(01):73-82

20 Wood K, Buttermann G, Mehbod A, Garvey T, Jhanjee R, Sechriest V. Operative compared with nonoperative treatment of a thoracolumbar burst fracture without neurological deficit. A prospective, randomized study. J Bone Joint Surg Am 2003;85(05):773-781

21 Siebenga J, Leferink VJM, Segers MJM, et al. Treatment of traumatic thoracolumbar spine fractures: a multicenter prospective randomized study of operative versus nonsurgical treatment. Spine 2006;31(25):2881-2890

22 Mehta JS, Reed MR, McVie JL, Sanderson PL. Weight-bearing radiographs in thoracolumbar fractures: do they influence management? Spine (Phila Pa 1976) 2004;29(05):564-567

23 Zhu Q, Shi F, Cai W, Bai J, Fan J, Yang H. Comparison of Anterior Versus Posterior Approach in the Treatment of Thoracolumbar Fractures: A Systematic Review. Int Surg 2015;100(06):1124-1133

24 Seybold EA, Sweeney CA, Fredrickson BE, Warhold LG, Bernini PM. Functional outcome of low lumbar burst fractures. A multicenter review of operative and nonoperative treatment of L3-L5. Spine 1999;24(20):2154-2161

25 Roberts JB, Curtiss PH Jr. Stability of the thoracic and lumbar spine in traumatic paraplegia following fracture or fracture-dislocation. J Bone Joint Surg Am 1970;52(06):1115-1130

26 Chance GQ. Note on a type of flexion fracture of the spine. Br J Radiol 1948;21(249):452-453

27 Miyanji F, Fisher CG, Keynan O, Wing PC, Boyd M, Dvorak MF. Flexion-distraction injuries of the thoracolumbar spine: healthrelated quality of life and radiographic outcomes. Top Spinal Cord Inj Rehabil 2006;12(01):58

28 Grossbach AJ, Dahdaleh NS, Abel TJ, Woods GD, Dlouhy BJ, Hitchon PW. Flexion-distraction injuries of the thoracolumbar spine: 
open fusion versus percutaneous pedicle screw fixation. Neurosurg Focus 2013;35(02):E2

29 Arkader A, Warner WC Jr, Tolo VT, Sponseller PD, Skaggs DL. Pediatric Chance fractures: a multicenter perspective. JPediatr Orthop 2011;31(07):741-744

30 Campbell A, Yen D. Late neurologic deterioration after nonoperative treatment of a Chance fracture in an adolescent. Can J Surg 2003;46(05):383-385

31 Liu YJ, Chang MC, Wang ST, Yu WK, Liu CL, Chen TH. Flexiondistraction injury of the thoracolumbar spine. Injury 2003;34 (12):920-923

32 Mikles MR, Stchur RP, Graziano GP. Posterior instrumentation for thoracolumbar fractures. JAm Acad Orthop Surg 2004;12(06): 424-435
33 Joaquim AF, Schroeder GD, Patel AA, Vaccaro AR. Clinical and radiological outcome of non-surgical management of thoracic and lumbar spinal fracture-dislocations - a historical analysis in the era of modern spinal surgery. J Spinal Cord Med 2018;21:1-7

34 van Middendorp JJ, Audigé L, Hanson B, Chapman JR, Hosman AJF. What should an ideal spinal injury classification system consist of? A methodological review and conceptual proposal for future classifications. Eur Spine J 2010;19(08):1238-1249

35 Vaccaro AR, Schroeder GD, Kepler CK, et al. The surgical algorithm for the AOSpine thoracolumbar spine injury classification system. Eur Spine J 2016;25(04):1087-1094

36 Schroeder GD, Kepler CK, Koerner JD, et al. Can a Thoracolumbar Injury Severity Score Be Uniformly Applied from T1 to L5 or Are Modifications Necessary? Global Spine J 2015;5(04):339-345 